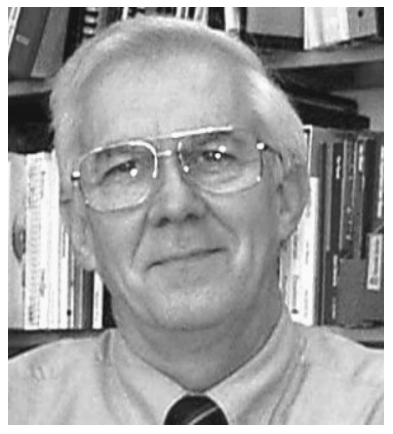

\section{1 in Review}

It has been customary to report on Optical Engineering at the end of each year, and thus this editorial describes the state of this journal at the end of 2001. My first impression looking at the size of the journal over the past three years is that after a large drop in size two years ago, the number of pages and papers bounced back strongly last year and this year the paper count, which I believe is more important than page count, dropped again slightly, as shown in Table 1. It is hard to pinpoint the reason for such a change, but some of the other trends may provide answers.

Part of the explanation may be found in the breakdown between regular papers and those submitted and published in special sections. Table 2 shows a drop of nearly $4 \%$ in regular papers published, but publication of special section papers decreased by more than $17 \%$. So most of the drop in papers might be attributed to fewer special sections. However, the number of special section papers has decreased in recent years by design. At one time they constituted one-third of all papers. One reason for the drop is that Brian Thompson and I phased out the "local" special sections ("Optics on the French Riviera") and encouraged both those who are in newly emerging fields and those in traditional optical engineering fields to assemble such sections. But it ain't easy. Despite their best efforts, editors of these sections find that it takes much the same effort as putting on a conference. One encouraging aspect of the journal statistics is that the number of regular papers submitted increased by nearly $5 \%$.

Another reason for the drop in the number of papers is that the percentage of the papers we accepted went down by $2 \%$ (see Table 3 ). This is not a good or bad number. There is no target acceptance quotient. However, the fact that the acceptance quotient remained constant as the number of submissions increased indicates that our reviewers and the Associate Editors take their assignments seriously.

Table 1 Major statistics for 2000-2001 and percentage changes from 2000.

\begin{tabular}{lrrc}
\hline \hline & 2000 & 2001 & 2001 vs 2000 \\
\hline Number of journal pages & 3360 & 2924 & $-13.0 \%$ \\
Number of technical pages & 3220 & 2776 & $-13.8 \%$ \\
Number of papers published & 412 & 385 & $-6.6 \%$ \\
\hline \hline
\end{tabular}

Although OE Letters was instituted in mid-2000 and submissions began to arrive late in the year, the first full year of publication has been, I believe, a good beginning. Certainly our standards as to what constitutes a "rapid publication of short technical communications of significant interest to optical scientists and engineers" have been fairly high since only one-third of the papers submitted are published, as is shown in Table 4. I expect this ratio to rise somewhat. It could be that authors didn't quite understand our standards and expectations.

In the main, these papers represent research that deserves to be brought to the attention of optical engineers in a timely manner. From that perspective I believe the value of Optical Engineering is enhanced. There is one additional aspect of this new enterprise that has not been examined, and therefore is not presented here-that is, the publication of these papers on SPIE Web as soon as they are accepted. We need to find the number of "hits" at this site. The papers can be accessed at http://spie.org/oe/ letters.

In order to show what appears to be a trend, I have included the data for 1999 in Table 5, which gives the distribution of first authors for papers published for the past three years. It would seem there is a definite increase in the number of papers from Asia over the past three years. And for the first time there are more papers from Asia than any other region. The contributions from other regions have changed little.

California continues to be the largest source of papers within the United States, although the output has dropped by one-third. The numbers in parentheses in Table 6 are the number of papers for the previous year.

One reason for the increased submissions from Asia may be the use of electronic submissions. Since Spring 1999 , the percentage of e-subs has grown from $20 \%$ in that year to $50 \%$ last year and to $67 \%$ this year. If you are not familiar with the procedure, you can find a description

Table 2 Regular vs special section papers for 2000-2001 and percentage changes from 2000.

\begin{tabular}{lrrcr}
\hline \hline & 2000 & 2001 & 2001 ratio & 2001 vs 2000 \\
\hline Regular papers published & 332 & 319 & $82.9 \%$ & $-3.9 \%$ \\
Special papers published & 80 & 66 & $17.1 \%$ & $-17.5 \%$ \\
Regular papers received & 525 & 549 & & $+4.6 \%$ \\
Special papers received & 29 & 73 & & $+151.7 \%$ \\
\hline \hline
\end{tabular}


Table 3 Outcomes of papers acted on in 2000 and 2001 (regular papers only; OE Letters not included).

\begin{tabular}{lrrrr}
\hline \hline & \multicolumn{2}{c}{2000} & \multicolumn{2}{c}{2001} \\
\hline Accepted & 295 & $62.25 \%$ & 317 & $60.04 \%$ \\
Declined & 106 & $22.36 \%$ & 146 & $27.65 \%$ \\
Closed & 67 & $14.14 \%$ & 57 & $10.80 \%$ \\
Withdrawn & 4 & $0.84 \%$ & 4 & $0.76 \%$ \\
Transferred & 2 & $0.42 \%$ & 4 & $0.76 \%$ \\
Total & 474 & $100 \%$ & 528 & $100 \%$ \\
\hline \hline
\end{tabular}

Table 4 OE Letters statistics for 2000 vs 2001 (began accepting submissions in August 2000).

\begin{tabular}{lccc}
\hline \hline & 2000 & 2001 & $\%$ \\
\hline Letters published & 0 & 20 & \\
Letters received & 22 & 61 & \\
Accepted & 3 & 25 & $33.3 \%$ \\
Declined & 3 & 50 & $66.7 \%$ \\
\hline \hline
\end{tabular}

Table 5 Number of papers published by region of first author in 1999, 2000, and 2001.

\begin{tabular}{lrrr}
\hline \hline Region & 1999 & 2000 & 2001 \\
\hline Africa & & 3 & 2 \\
Asia & 77 & 119 & 145 \\
Australia & 8 & 7 & 2 \\
Eastern Europe & 13 & 19 & 14 \\
Middle East & 10 & 18 & 14 \\
North America & 108 & 163 & 121 \\
South/Central America & 6 & 4 & 8 \\
Western Europe & 51 & 79 & 79 \\
\hline \hline
\end{tabular}

Table 6 Number of papers published from the U.S. in 2001 by state of first author. (Numbers in parentheses are the 2000 figures.)

\begin{tabular}{lc}
\hline \hline State & Number \\
\hline California (23) & 14 \\
Texas (12) & 10 \\
Massachusetts (11) & 8 \\
Arizona (9); Virginia (5) & 6 \\
New York (5); Ohio (5) & 5 \\
Alabama; New Jersey & 4 \\
Florida; Georgia; Maryland; New Mexico; Tennesee & 3 \\
Arkansas; Colorado; Illinois; Michigan; Pennsylvania; & \\
South Carolina & 2 \\
Connecticut; Delaware; Idaho; Kentucky; Montana; & \\
Nebraska; New Hampshire: Oklahoma; Oregon; & \\
Washington, DC & 1 \\
\hline \hline
\end{tabular}

Table 7 Activity of the editorial office in 2001 (regular papers only, including $O E$ Letters).

\begin{tabular}{lrc}
\hline \hline & Number & \% change vs 2000 \\
\hline Reviewers selected & 2023 & +8.70 \\
Reviews received & 881 & +4.14 \\
Revised manuscripts received & 335 & +6.35 \\
Papers returned to authors & 399 & +2.84 \\
$\quad$ for revision & & -72.22 \\
Communication papers received & 5 & +177.27 \\
$O E$ Letters received & 61 & \\
\hline \hline
\end{tabular}

on SPIE Web by typing in http://spie.org/oe and clicking on the Author Information tab.

The review process also benefits from this electronic procedure. Both Associate Editor assignments and reviewer assignments are done by e-mail. Requests to review are done by e-mail with a pdf file containing the abstract attached. With the increased number of papers, the number of reviewers has increased, but the number of reviews has also increased (Table 7). There is a considerable difference between the number of reviewers that were asked to review and the number of reviews received. This doesn't mean that a lot of reviewers are not responding. It is probably a measure of the willingness of those reviewers we asked to review to do so. Also, many of these reviews were initiated at the end of 2001 and are still in progress.

Although there are always a few papers for which it seems to take forever to arrive at a decision, the response times have been reduced. If the reviewer wishes, we can now send the complete manuscript as a pdf file, also. I thank all of our reviewers who contributed to maintaining the high standards we have come to expect.

I want to thank the members of the Board of Editors for their contributions toward maintaining these standards. I thank Bahram Javidi and Mike Feldman, who have stepped off the Board of Editors, for their effort, and Bill Spillman, who will be leaving us early this year. I appreciate the additional help that new Associate Editors Jiangying Zhou and Touradj Ebrahimi provide to Andy Tescher in information processing, and the expertise that Greg Quarles brings to the assignment and evaluation of papers on lasers.

While the members of the Board of Editors get their timely messages in their e-mail inboxes each week (for me, it's daily), the continuous work of keeping us on track and making sure the reviewers are reminded, the papers are copy edited, and this collection of pages you hold in your hand gets printed is done by the SPIE journals staff. You will find their names on the masthead of this journal. What they may lack in an understanding of our field, they make up in an attention to the details of publication and a devotion to getting it right and developing our electronic procedures. They have been instrumental in establishing and improving our electronic review process. I am proud to be associated with such a great group of people, the journals staff and the Board of Editors. To be able to assist in providing the optical engineering community with a record of its progress is a wonderful thing. Thank you.

Donald C. O'Shea Editor 